\title{
Recursos no Ambiente Familiar e Dificuldades de Aprendizagem na Escola'
}

\author{
Edna Maria Marturano² \\ Universidade de São Paulo, Ribeirão Preto
}

\begin{abstract}
RESUMO - Recursos do ambiente familiar, que favorecem o desempenho escolar, incluem materiais educacionais e envolvimento parental. Realizou-se um estudo com o objetivo de investigar esses recursos em uma amostra clínica de 100 crianças, encaminhadas por dificuldades na aprendizagem escolar. Os dados foram coletados durante entrevista com a mãe, por meio de um roteiro para sondagem de recursos e circunstâncias adversas. À criança era solicitado um texto a partir de um desenho. A análise estatística incluiu análise de regressão, correlação e comparação entre médias de subgrupos constituídos segundo idade, atraso escolar e desempenho na escrita. Os resultados indicaram que o nível de elaboração da escrita está positivamente associado à disponibilidade de livros e brinquedos, enquanto o atraso escolar está negativamente associado à organização das rotinas e à diversidade de atividades compartilhadas com os pais. Circunstâncias adversas têm associação positiva com atraso. Os resultados são discutidos quanto à sua aplicabilidade em programas de orientação psicopedagógica às famílias.
\end{abstract}

Palavras-chave: desempenho escolar; criança; recursos ambientais; envolvimento parental.

\section{Home Resources and School Learning Difficulties}

\begin{abstract}
Home resources which promote school achievement include educational materials and parent involvement with children's schooling. A study was performed with the aim of investigating these resources in a clinical sample of 100 children, who were referred for school learning problems. The data were collected with the mother, by means of a interview designed for the assessment of home resources and adversities. The child was asked to write a text from a drawing. Statistical analysis included regression analysis, correlation and comparisons between groups formed by age, school backwardness, and writing performance. Results indicated that writing level is positively related with the provision of books and toys, while school backwardness is negatively related with regularity in the use of time and with diversity of activities shared with parents. Adverse life circumstances have a positive association with backwardness. These results are discussed with respect to their contribution to educational programs for the families.
\end{abstract}

Key words: school achievement; child; home resources; parental involvement.

$\mathrm{O}$ trato com os problemas de aprendizagem no contexto da clínica-escola deve fundamentar-se em pressupostos teóricos capazes de instrumentar o profissional em formação com recursos conceituais adequados à natureza dos processos envolvidos. No estudo empírico descrito neste texto, variáveis do ambiente familiar associadas a desempenho escolar são focalizadas a partir de uma perspectiva desenvolvimentista, direcionada para mecanismos envolvendo risco, proteção e vulnerabilidade (Rutter, 1987). Nessa visão, escola e família constituem sistemas nos quais a criança está inserida e onde deve desempenhar papéis diversos, às vezes conflitantes; e a experiência escolar pode contribuir para diferentes trajetórias de desenvolvimento, segundo seu impacto sobre as experiências futuras do indivíduo. No caso da criança que fracassa, a escola, que em princípio poderia prover mecanismos protetores, aparece como instância que contribui para aumentar a vulnerabilidade frente a riscos, em

1 Este trabalho recebeu apoio do CNPq sob forma de bolsa de pesquisa para a autora. Uma versão resumida foi apresentada ao Grupo de Trabalho Atendimento Psicológico nas Clínicas-Escola, durante o VII Simpósio de Pesquisa e Intercâmbio Científico da ANPEPP, Gramado, em maio de 1998. A autora agradece às psicólogas Iara Cristina Camparis Degani, Margaret Rose Santa e Vera Lúcia Parreira pela colaboração na coleta de dados.

2 Endereço: Av. 9 de Julho, 980. CEP: 14025-000 Ribeirão Preto - SP. E-mail: emmartur@netsite.com.br particular no ponto de transição que caracteriza o momento de ingresso no ensino formal. Sobressai, então, a influência do ambiente familiar como a principal fonte de recursos a que a criança pode recorrer para lidar com os desafios do processo de integração à escola, primeiro passo no percurso de sua integração à sociedade.

Os investigadores têm reconhecido a importância das influências familiares na escolarização. A investigação de variáveis distais vem documentando associações positivas entre status sócio-econômico e educacional dos pais e o desempenho escolar da criança (Stevenson \& Baker, 1987). A tendência atual no estudo desses efeitos parece ser de focalizar variáveis proximais, associadas principalmente ao envolvimento parental, às práticas educativas e à organização do ambiente do lar (Bradley, Caldwell \& Rock, 1988; Grolnick \& Ryan, 1992; Martini, 1995; Stevenson \& Baker, 1987). Os estudos que tratam de envolvimento dos pais, estilos parentais e organização no lar, em geral, enfatizam os efeitos positivos de práticas e recursos promotores do desenvolvimento (Bradley \& cols., 1988; Kellaghan, Sloane, Alvarez e Bloom, 1993; Luster \& McAdoo, 1994). O impacto de condições adversas é investigado nos trabalhos que focalizam seja o binômio estresse/suporte, o relacionamento do casal parental ou a qualidade do funcionamento da família (Dubois, Felner, Brand, Adan \& Evans, 1992; Dubow \& Tisak, 1989; Feldman \& Wentzel, 1990; Masten \& cols., 


\section{E. M. Marturano}

1988). Alguns estudos têm conseguido determinar, no sistema constituído pelas atividades, papéis e relações interpessoais vividos pela criança, mecanismos que afetam as relações entre interação pais-filhos e desempenho escolar (Feldman \& Wentzel, 1990; Grolnick \& Slowiaczek, 1994).

Os estudos citados sugerem que a presença de recursos no ambiente familiar tem impacto positivo sobre o desempenho escolar, quando inclui uma combinação entre dois conjuntos de condições: (a) experiências ativas de aprendizagem, que promovem competência cognitiva; (b) um contexto social em que o estilo de interação e relações promove autoconfiança e interesse ativo em aprender independentemente da instrução formal. Por outro lado, circunstâncias adversas, como discórdia conjugal e familiar, parecem afetar negativamente o desenvolvimento socioemocional.

$\mathrm{Na}$ tentativa de compreender os processos por meio dos quais o ambiente familiar afeta o desempenho escolar da criança, Bradley e cols. (1988) investigaram três modelos de ação ambiental: primazia das primeiras experiências, primazia do ambiente contemporâneo e efeitos de condições estáveis. Para testar os modelos, acompanharam, durante dez anos, crianças que em sua maioria eram filhas de trabalhadores; avaliaram seu ambiente familiar por meio do inventário $H O M E$ quando elas tinham seis meses, dois anos e dez anos de idade. Cada modelo teve algum apoio empírico, havendo evidências mais fortes para a ação do ambiente contemporâneo. Verificou-se que pais que fizeram arranjos para que seus filhos estivessem envolvidos com uma gama de experiências sociais e culturais durante os anos de escola elementar tinham filhos com melhor desempenho escolar global, em matemática e em linguagem. Além disso, as crianças eram mais ajustadas na escola. Essas relações foram independentes das características do ambiente familiar anteriores à escolarização.

Em síntese, investigações conduzidas na população geral sugerem que recursos do ambiente familiar que favorecem o desempenho escolar incluem presença de materiais educacionais e envolvimento dos pais, na forma de interação, compartilhamento de atividades, supervisão e organização das rotinas. Cabe perguntar em que extensão esses achados se aplicam à nossa realidade nas clínicas-escola, cuja clientela infantil está constituída, na maioria, por crianças com dificuldades escolares (Silvares, 1993).

Esse segmento da clientela das clínicas-escola apresenta, como grupo, características psicológicas que o diferenciam, em vários aspectos, da população de crianças com baixo desempenho escolar, cujas famílias não buscam atendimento psicológico (Marturano, Linhares, Loureiro \& Machado, 1997). As diferenças encontradas não se reportam a sinais psicopatológicos no grupo clínico, mas sugerem menor acesso a recursos pessoais para o enfrentamento das situações cotidianas. Há indícios de que uma parcela não pequena desse grupo está exposta a circunstâncias adversas na vida pessoal, familiar e escolar (Marturano, Magna \& Murtha, 1993). O quadro delineado é compatível com uma concepção sistêmica em que o baixo desempenho escolar não pode ser visto isoladamente, seja como um problema pedagógi- co, seja como uma dificuldade individual. Ao contrário, deve ser referido aos contextos de desenvolvimento da criança.

Os problemas escolares nessa amostra clínica podem, assim, ser considerados como dificuldades de aprendizagem, de acordo com o conceito desenvolvido por Almeida e cols. (1995). O conceito, descritivo dos fatores precipitantes do baixo desempenho escolar, difere essencialmente do de distúrbio de aprendizagem, pois não situa a origem da dificuldade no indivíduo, mas nas interações entre características pessoais e fatores relacionados ao núcleo familiar, à escola e ao meio social.

Considerando a generalidade das "dificuldades de aprendizagem" enquanto motivo de procura dos serviços de Psicologia, foi realizado o estudo empírico relatado neste texto, com o objetivo de verificar a disponibilidade de recursos associados ao desempenho acadêmico em famílias de crianças encaminhadas por dificuldades na aprendizagem escolar. Investigações anteriores sugerem que a distribuição de tais recursos nessa população específica varia em função da idade da criança, da escolaridade da mãe e do indicador de desempenho escolar empregado - se baseado em avaliação direta da criança ou derivado de informações sobre a vida escolar (Marturano, 1997; Marturano, Santos, Dela Coleta \& Matos, 1997). No delineamento da investigação, essas informações foram levadas em conta.

Espera-se com este estudo fornecer subsídios às clínicas-escola de Psicologia, para a implementação de práticas de orientação psicopedagógica às famílias, bem como de programas de capacitação do psicólogo para atuar nesse campo de sua competência.

\section{Método}

\section{Sujeitos}

Participaram da pesquisa 100 crianças inscritas para atendimento em uma clínica de Psicologia vinculada a um hospital universitário. Todas haviam sido encaminhadas, através de referência do Sistema Único de Saúde, tendo por motivo de encaminhamento queixas escolares. A Tabela 1 apresenta uma caracterização dessa amostra quanto ao sexo, à idade, à escolaridade, aos anos de atraso escolar, à escolaridade da mãe, à jornada de trabalho da mãe e à composição familiar básica.

\section{Local}

A investigação foi conduzida em uma clínica-escola cuja proposta de atendimento à clientela com dificuldades escolares focaliza os recursos da criança e da família, no sentido de identificá-los e mobilizá-los para enfrentamento dos problemas em curso.

\section{Procedimento}

Dados demográficos das famílias foram obtidos da ficha preenchida no momento da inscrição. Na primeira consulta agendada após a inscrição, a mãe e a criança eram vistas separadamente por uma psicóloga da equipe. Por meio de 
Tabela 1 - Características da amostra

\begin{tabular}{|c|c|c|}
\hline \multicolumn{2}{|c|}{ Variável } & $\%$ \\
\hline \multirow[t]{2}{*}{ Sexo } & masc & 67 \\
\hline & fem & 33 \\
\hline Idade & $7-8$ anos & 52 \\
\hline \multirow[t]{2}{*}{$(n=90)$} & $9-10$ anos & 37 \\
\hline & $11-12$ anos & 11 \\
\hline Série que cursa & 1 a & 44 \\
\hline \multirow[t]{3}{*}{$(n=90)$} & $2^{\mathrm{a}}$ & 47 \\
\hline & $3^{\mathrm{a}}$ & 5 \\
\hline & classe especial / não estuda & 4 \\
\hline \multirow{3}{*}{$\begin{array}{l}\text { A traso escolar em anos } \\
(\mathrm{n}=90)\end{array}$} & nenhum & 45 \\
\hline & um & 32 \\
\hline & dois ou mais & 23 \\
\hline \multirow{4}{*}{$\begin{array}{l}\text { Escolaridade da mãe } \\
(\mathrm{n}=90)\end{array}$} & analfabeta & 6 \\
\hline & de 1 a 4 anos & 45 \\
\hline & de 5 a 8 anos & 28 \\
\hline & acima de 8 anos & 21 \\
\hline \multirow{4}{*}{$\begin{array}{l}\text { Jornada de trabal ho da mãe } \\
(\mathrm{n}=90)\end{array}$} & acima de 8 horas & 33 \\
\hline & entre 5 e 8 horas & 18 \\
\hline & até 4 horas & 5 \\
\hline & trabalha em casa & 44 \\
\hline \multirow{3}{*}{$\begin{array}{l}\text { Flexibilidade do horário de } \\
\text { trabal ho da mãe }(n=90)^{*}\end{array}$} & horário rígido & 17 \\
\hline & horário flexível ou negociável & 37 \\
\hline & horário sob controle da mãe & 46 \\
\hline \multirow{5}{*}{$\begin{array}{l}\text { Composição familiar } \\
\text { - criança mora com: }\end{array}$} & mãe e pai biológicos & 62 \\
\hline & somente a mãe & 13 \\
\hline & mãe e pai substituto & 13 \\
\hline & mãe e pai adotivos & 4 \\
\hline & outros & 8 \\
\hline
\end{tabular}

* Horário rígido: mãe com ocupação fixa em empresa privada ou órgão público; horário flexível ou negociável: mãe diarista em residência; horário sob controle da mãe: comerciante, autônoma ou do lar.

entrevista com a mãe, eram colhidos dados sobre recursos do ambiente e informações sobre a vida escolar e eventos/ circunstâncias adversas. À criança era solicitado um desenho livre e um texto sobre este desenho. Esse procedimento faz parte da rotina de atendimento na clínica.

\section{Instrumentos e Medidas}

Foram incluídas no estudo medidas relativas à criança e ao ambiente. Em relação à criança, trabalhou-se com dois indicadores de desempenho escolar. O atraso escolar, derivado de informações sobre a vida escolar, foi determinado computando-se a diferença entre a série cursada e a esperada a partir da idade da criança. O nível de elaboração da escrita, baseado em avaliação direta da criança, foi obtido mediante a tarefa de escrita de texto. A produção escrita da criança, solicitada a partir de um desenho livre, foi classificada em quatro níveis de elaboração: (1) intenção de escrita (garatuja / apenas o próprio nome / letras / sílabas / pseudopalavras); (2) escreve palavras; 3 . escreve frase(s); 4. escreve um texto coerente, articulando frases por meio de elementos coesivos.
Em relação ao ambiente, foram consideradas variáveis relativas a recursos e circunstâncias adversas. Os instrumentos para obtenção das informações são descritos a seguir.

\section{Recursos do Ambiente Familiar}

Os dados sobre recursos foram coletados por meio do Roteiro para Sondagem de Recursos no Ambiente Familiar (RAF), elaborado com o objetivo de rastrear informações sobre condições relevantes para o desempenho acadêmico. Aplica-se o roteiro sob forma de entrevista semi-estruturada, em que cada tópico é apresentado à mãe oralmente, tendo o examinador liberdade para parafrasear o conteúdo da questão caso haja dificuldade de compreensão por parte da entrevistada. Em cada tópico, o entrevistador inicia fazendo uma pergunta aberta. Em seguida, apresenta os itens de questões fechadas.

O RAF é constituído de 14 tópicos, com um número variável de itens, reunidos em três módulos: supervisão e organização das rotinas, oportunidades de interação com os pais e presença de recursos no ambiente físico. O módulo supervisão e organização das rotinas inclui os tópicos: o que a criança faz quando não está na escola; ajuda e responsabilidade em tarefas domésticas; arranjo espaço-temporal para lição de casa; supervisão para a escola; atividades diárias com horário definido. O módulo Oportunidades de interação com os pais inclui: passeios proporcionados/compartilhados; atividades compartilhadas pela criança e os pais no lar; ocasiões em que a família está reunida; pessoas a quem a criança recorre para pedir ajuda ou conselho. $\mathrm{O}$ módulo Presença de recursos no ambiente físico inclui: atividades programadas que a criança realiza regularmente; disponibilidade de livros; disponibilidade de jornais/revistas; oferta de brinquedos e outros materiais promotores do desenvolvimento; presença de eletrodomésticos e outras comodidades. Em cada módulo, o número e o formato dos itens são variados. $\mathrm{O}$ escore total corresponde à soma das médias dos 17 escores obtidos nos 14 tópicos do RAF, sendo essas médias o resultado da divisão do escore em cada uma das medidas pelo número de itens que compõem essa medida.

Para construção do instrumento, foi feito inicialmente um levantamento de recursos em prontuários da clínica (Marturano, Alves \& Santa Maria, 1998), com base em indicações de Kellaghan e cols. (1993), Bradley e cols. (1988) e Christensen (1990). As descrições de recursos contidas nos prontuários foram usadas para formulação dos itens. Uma primeira versão do roteiro foi organizada em módulos, conforme a listagem elaborada por Kellaghan e cols. (1993). O roteiro foi pré-testado em amostra de 20 famílias, por três psicólogos com experiência em condução de entrevista. Após 15 entrevistas, os psicólogos, reunidos com a pesquisadora, apresentaram sugestões de mudança que foram incorporadas. Uma nova reunião feita depois de cinco aplicações do roteiro modificado não acrescentou mudanças, encerrandose, então, a fase de pré-teste. Um estudo de fidedignidade por meio do procedimento teste-reteste com três mães forneceu índices de 100\%, 99\% e 92\% de concordância entre 
aplicações feitas com 20 dias de intervalo (Santos, 1999). Dois tópicos ilustrativos do RAF são apresentados no Anexo.

\section{Eventos adversos}

Foram obtidos dados sobre circunstâncias adversas por meio de um formulário pré-testado junto ao RAF. Eventos adversos ocorridos nos últimos 12 meses ou anteriormente na vida da criança foram investigados por meio de uma lista de 36 situações que podem ocorrer na vida escolar (cinco itens), familiar (26 itens) ou pessoal (cinco itens), elaborada a partir dos estudos de Rende e Plomin (1991) e Berden, Althaus e Verhulst (1990). Para aplicação, o entrevistador diz à mãe que vai ler uma lista de situações que podem acontecer na vida das crianças, para que ela informe se alguma delas ocorreu com seu filho/sua filha. Em seguida, lê cada item do formulário e pede à mãe que diga se o evento ocorreu nos últimos 12 meses ou anteriormente na vida da criança. Preenche-se cada item com X na coluna apropriada. Se o evento ocorreu tanto nos últimos 12 meses como anteriormente, marca-se $\mathrm{X}$ nas duas colunas. Atribui-se a cada item o escore zero, um ou dois, e o escore total é a soma dos escores individuais, podendo variar de zero a 72 .

\section{Adversidade crônica}

A partir de informações dadas espontaneamente pelas mães nas entrevistas de pré-teste, acrescentou-se uma lista de 14 condições adversas crônicas, definidas como adversidade prolongada (com duração de mais de 12 meses) ou recorrente (ocorrência repetida durante um ano ou mais), cujo escore é a simples contagem de incidência.

\section{Procedimento de análise de dados}

Os escores obtidos nos três instrumentos de avaliação do ambiente foram convertidos em escores $z$ com média igual a zero e desvio padrão igual a um.

A presença de recursos e condições adversas no ambiente familiar foi analisada em relação a dois indicadores de desempenho escolar: atraso escolar e nível de elaboração da escrita. Em virtude da relação direta entre atraso escolar e idade, e das associações previamente encontradas entre idade e presença de recursos no ambiente familiar, assim como entre escolaridade da mãe e desempenho escolar, a idade da criança e a escolaridade materna foram incluídas na análise.

A relação entre os escores totais nos três instrumentos de avaliação do ambiente e os indicadores de desempenho escolar foi verificada por meio da análise de regressão múltipla, incluindo-se no modelo a escolaridade materna e a idade da criança.

A associação entre a pontuação obtida em cada um dos 14 tópicos do RAF e as variáveis escolaridade da mãe, idade e atraso escolar foi verificada por meio do índice de correlação $r$ de Pearson. O teste $t$ de Student foi usado para comparação entre subgrupos constituídos segundo o desempenho na escrita. $O$ grupo que apresentou apenas intenção de escrita $(n=35)$ foi comparado com o grupo formado pelas crianças que produziram frases ou texto $(n=19)$.
Para verificar a associação entre cada item do RAF e as variáveis da criança, foi empregado o teste qui-quadrado, já que os itens têm formato de escala nominal, fornecendo dados de presença ou ausência de um determinado recurso. Para aplicar essa análise às variáveis idade e atraso escolar, essas variáveis foram dicotomizadas. Assim, em relação à idade, foi constituído um grupo com crianças de 7 a 8 anos $(n=46)$ e um grupo com crianças de 9 a 12 anos $(n=43)$. Para verificar a distribuição dos itens segundo o atraso escolar, foi constituído um grupo sem atraso $(n=40)$ e um grupo com atraso de dois anos ou mais $(n=21)$.

Foi considerado significativo todo resultado com probabilidade igual ou inferior a 0,05 . Como os cálculos envolveram diversas variáveis, as probabilidades associadas aos valores de $r$ e de $t$ foram ajustadas (procedimento de Bonferroni).

\section{Resultados}

O RAF mostrou alguma consistência interna, indicada por um coeficiente alfa igual a 0,74 . Os tópicos significativamente correlacionados são apresentados na Tabela 2.

Observa-se que as classes de recursos relativos a passeios proporcionados/compartilhados nos últimos 12 meses, atividades compartilhadas pela criança e os pais no lar, disponibilidade de livros e oferta de brinquedos estão todas correlacionadas entre elas. As classes arranjo espaço-temporal para lição de casa e atividades diárias com horário definido compõem uma associação à parte. $\mathrm{O}$ item eletrodomésticos e outras comodidades tem correlação com diversas classes de recursos.

O escore total no RAF apresentou correlação positiva significativa com escolaridade da mãe $(r=0,34, p=0,004)$. A variável escolaridade da mãe mostrou correlação positiva também com os tópicos disponibilidade de livros $(r=0,48$, $p<0,0001)$, oferta de brinquedos e outros materiais promotores do desenvolvimento $(r=0,33, p=0,022)$ e presença de eletrodomésticos e outras comodidades $(r=0,45, p<0,0001)$.

Os resultados das análises de regressão são apresentados na Tabela 3.

As Tabelas 4 e 5, apresentando resultados relativos a itens específicos do RAF, complementam as informações contidas na Tabela 3.

Os resultados apresentados na Tabela 3 foram obtidos com um modelo de análise que incluiu as seguintes variá-

Tabela 2 - Itens do RAF com correlações significativas ( $r$ de Pearson)

\begin{tabular}{|c|c|c|c|c|c|c|c|c|}
\hline Item & LC & $\mathbf{A H}$ & $\mathbf{P}$ & $\mathbf{A P}$ & $\mathbf{L}$ & J R & B & $\mathrm{C}$ \\
\hline LC lição de casa & & $0,40^{b}$ & - & - & - & - & - & - \\
\hline AH atividade com horário & & & - & - & - & - & - & $0,35^{\mathrm{a}}$ \\
\hline P passeios & & & & $0,37^{\mathrm{a}}$ & $0,37^{\mathrm{a}}$ & - & $0,42^{c}$ & $0,39^{b}$ \\
\hline AP atividade com os pais & & & & & $0,35^{\mathrm{a}}$ & - & $0,41^{b}$ & - \\
\hline L livros & & & & & & $0,37^{\mathrm{a}}$ & $0,44^{c}$ & $0,44^{c}$ \\
\hline JR jornais/revistas & & & & & & & - & - \\
\hline B brinquedos & & & & & & & & $0,61^{c}$ \\
\hline C comodidades & & & & & & & & \\
\hline
\end{tabular}

${ }^{\mathrm{a}} p<0,05 \quad{ }^{\mathrm{b}} p<0,01 \quad{ }^{\mathrm{c}} p<0,001$ 
Tabela 3 - Variância nas medidas de desempenho escolar explicadas por medidas globais de recursos e adversidades no ambiente, incluindo-se a idade e a escolaridade materna na análise de regressão múltipla.

\begin{tabular}{lccc}
\hline M edidas de desempenho & & & \\
\hline Atraso escolar & $\mathbf{F}$ & $\mathbf{R}^{2}$ & $\mathbf{p}$ \\
Idade & 116,99 & 0,69 & 0,001 \\
Adversidade crônica & 4,26 & 0,02 & 0,04 \\
Elaboração da escrita & $\mathbf{F}$ & $\mathbf{R}^{2}$ & $\mathbf{p}$ \\
Idade & 4,59 & 0,04 & 0,04 \\
Recursos (escore total no RA F) & 5,91 & 0,07 & 0,02 \\
Adversidade crônica & 4,16 & 0,06 & 0,05 \\
\hline
\end{tabular}

Tabela 4 - Diferenças significativas associadas à idade, detectadas pelo teste $X^{2}$

\begin{tabular}{lccc}
\hline \multirow{2}{*}{ Variável } & \multicolumn{2}{c}{$\%$} & \\
\cline { 2 - 3 } & mais jovens mais vel hos & \multirow{2}{*}{$X^{2}$} \\
\cline { 2 - 3 } & $\mathrm{n}=47$ & $\mathrm{n}=43$ & \\
\hline $\begin{array}{l}\text { Ajuda em tarefas domésticas } \\
\text { ocasional mente }\end{array}$ & 50 & 74 & $6,330^{*}$ \\
$\begin{array}{l}\text { Recorre a um irmão quando } \\
\text { precisa de ajuda }\end{array}$ & 4 & 19 & $4,529^{*}$ \\
$\begin{array}{l}\text { Faz lição em qual quer lugar } \\
\begin{array}{l}\text { Fez passeio em zoológico } \\
\text { (últimos 12 meses) }\end{array}\end{array}$ & 4 & 23 & $6,811^{* *}$ \\
\hline
\end{tabular}

Nota: Os cálculos foram efetuados sobre valores de freqüência. $* p<0,05 \quad * * p<0,01$

Tabela 5 - Diferenças significativas associadas ao atraso escolar, detectadas pelo teste $X^{2}$

\begin{tabular}{|c|c|c|c|}
\hline \multirow{3}{*}{ Variável } & \multicolumn{2}{|c|}{$\%$} & \multirow{3}{*}{$x^{2}$} \\
\hline & sem atraso & com atraso & \\
\hline & $\mathrm{n}=40$ & $\mathrm{n}=21$ & \\
\hline $\begin{array}{l}\text { Tem hora certa para levantar-se } \\
\text { de manhã }\end{array}$ & 80 & 53 & $5,911^{*}$ \\
\hline Tem hora certa para jantar & 67 & 38 & $5,143^{*}$ \\
\hline $\begin{array}{l}\text { Tem hora certa para fazer lição } \\
\text { de casa }\end{array}$ & 75 & 33 & $10,958^{* *}$ \\
\hline $\begin{array}{l}\text { Fez passeio em zoológico } \\
\text { (últimos } 12 \text { meses) }\end{array}$ & 40 & 9 & $6,149^{*}$ \\
\hline $\begin{array}{l}\text { Foi ao parque de diversões } \\
\text { (últimos } 12 \text { meses) }\end{array}$ & 45 & 19 & $4,022^{*}$ \\
\hline $\begin{array}{l}\text { Faz catecismo/estudos } \\
\text { bíblicos/evangelização }\end{array}$ & 15 & 43 & $5,763^{*}$ \\
\hline $\begin{array}{l}\text { Tem/teve brinquedo para } \\
\text { movimentar corpo }\end{array}$ & 50 & 24 & $3,905^{*}$ \\
\hline $\begin{array}{l}\text { Tem/teve } \\
\text { brinquedo/instrumento musical }\end{array}$ & 42 & 14 & $4,974^{*}$ \\
\hline $\begin{array}{l}\text { Tem/teve brinquedo para } \\
\text { conhecer nomes animais }\end{array}$ & 40 & 14 & $4,246^{*}$ \\
\hline Em casa há videocassete & 45 & 19 & $4,022^{*}$ \\
\hline
\end{tabular}

Nota: Os cálculos foram efetuados sobre valores de freqüência. $* p<0,05 \quad * * p<0,01$ veis independentes: idade, escolaridade da mãe, escore total no RAF, total de adversidades crônicas e total de eventos adversos. Apenas as relações significativas estão incluídas na tabela. A variável escolaridade da mãe não contribui para a variância nas medidas de desempenho escolar. A idade da criança, por outro lado, responde por $69 \%$ da variância na medida de atraso escolar. Os valores de $\mathrm{R}^{2}$ para as medidas de recursos e adversidades são modestos e diferem em suas relações com os indicadores de desempenho escolar. Enquanto $\mathrm{o}$ atraso escolar tem discreta relação direta com adversidade ambiental, o nível de elaboração da escrita tem relação direta com a presença de recursos e relação inversa com a presença de adversidade.

Conforme sugerem os resultados nas Tabelas 4 e 5, há recursos específicos que aparecem negativamente associados ao atraso, sem associação com idade. Esses recursos dizem respeito a algumas atividades com horário definido e à disponibilidade de brinquedos.

As medidas do RAF que diferenciaram os dois grupos constituídos a partir da variável elaboração da escrita são apresentadas nas tabelas 6 e 7 .

Tabela 6 - Diferenças significativas associadas ao nível de elaboração da escrita, detectadas pelo teste $t$ de Student

\begin{tabular}{llll}
\hline \multirow{3}{*}{ Variável } & \multicolumn{2}{c}{$\begin{array}{c}\text { M édias dos grupos } \\
\text { (escore z) }\end{array}$} & \\
\cline { 2 - 3 } & $\begin{array}{c}\text { intenção de } \\
\text { escrita }\end{array}$ & $\begin{array}{c}\text { escrita de } \\
\text { frases/texto }\end{array}$ & \\
\cline { 2 - 3 } & $\mathrm{n}=35$ & $\mathrm{n}=19$ & \\
\hline Disponibilidade de livros & $-0,332$ & 0,401 & $-2,702^{*}$ \\
Oferta de brinquedos & $-0,304$ & 0,480 & $-2,967^{*}$ \\
\hline
\end{tabular}

${ }^{*} p<0,05$

Tabela 7 - Diferenças significativas associadas ao nível de elaboração da escrita, detectadas pelo teste $X^{2}$

\begin{tabular}{|c|c|c|c|}
\hline \multirow{3}{*}{ Variável } & \multicolumn{2}{|c|}{$\%$ nos grupos } & \multirow{3}{*}{$x^{2}$} \\
\hline & $\begin{array}{l}\text { intenção de } \\
\text { escrita }\end{array}$ & $\begin{array}{l}\text { escrita de } \\
\text { frases/texto }\end{array}$ & \\
\hline & $n=35$ & $\mathrm{n}=19$ & \\
\hline $\begin{array}{l}\text { Quando não está na escola joga } \\
\text { videogame }\end{array}$ & 26 & 74 & $11,589 * * *$ \\
\hline Faz lição antes de ir brincar & 37 & 68 & $4,826^{*}$ \\
\hline Joga videogame com os pais & 17 & 63 & $11,734 * * *$ \\
\hline $\begin{array}{l}\text { Tem/teve livrinhos de histórias } \\
\text { infantis }\end{array}$ & 34 & 74 & $7,657^{* *}$ \\
\hline $\begin{array}{l}\text { Tem/teve brinquedo que lida } \\
\text { com números }\end{array}$ & 46 & 79 & $5,562 *$ \\
\hline $\begin{array}{l}\text { Tem/teve brinquedo de faz de } \\
\text { conta }\end{array}$ & 46 & 74 & $3,902 *$ \\
\hline $\begin{array}{l}\text { Tem/teve brinquedo de } \\
\text { construção }\end{array}$ & 23 & 58 & 6,629 \\
\hline Em casa há dicionário & 43 & 89 & $11,085^{* * *}$ \\
\hline Em casa há videogame & 31 & 63 & $5,070 *$ \\
\hline Em casa há videocassete & 26 & 58 & $5,469 *$ \\
\hline
\end{tabular}

Nota: Os cálculos foram efetuados sobre valores de freqüência. $* p<0,05 . * * p<0,01$ 


\section{E. M. Marturano}

Os resultados indicam que o nível de elaboração da escrita está positivamente associado à disponibilidade de livros e brinquedos estimuladores do desenvolvimento. A análise dos itens específicos confirma essa tendência e acrescenta algumas informações. As crianças que apresentam uma escrita mais elaborada fazem lição antes de ir brincar, têm ou tiveram livros infantis e dispõem de dicionário em casa. Além da oferta maior de brinquedos, contam com a possibilidade maior de compartilhar atividades com os pais. Comparando-se as porcentagens dos dois grupos quanto aos itens relacionados ao "videogame", que aparecem na Tabela 7 , verifica-se que no grupo com desempenho mais pobre $31 \%$ têm esse tipo de brinquedo em casa, mas apenas $17 \%$ jogam com os pais, ao passo que no grupo com melhor desempenho, o percentual de crianças que têm "videogame" é idêntico ao das que jogam "videogame" com seus pais.

\section{Discussão}

A investigação relatada neste texto teve como objetivo verificar a disponibilidade de recursos específicos associados ao desempenho acadêmico em famílias de crianças referidas pelo sistema de saúde a uma clínica-escola por dificuldades na aprendizagem escolar. Dois indicadores indiretos de desempenho escolar foram utilizados - um índice de atraso, dado pela diferença entre a série cursada e a esperada pela idade da criança, e um escore derivado da avaliação da produção escrita. Os resultados sugerem que o progresso na aprendizagem escolar, indicado seja pela ausência de atraso ou pela qualidade da produção escrita, está associado à supervisão e à organização das rotinas no lar, a oportunidades de interação com os pais e à oferta de recursos no ambiente físico. A presença de horários definidos para atividades diárias, inclusive a lição de casa, a oportunidade de compartilhar atividades com os pais e a diversidade de livros e brinquedos disponíveis para a criança compõem o conjunto de condições que diferenciaram, nessa amostra de crianças com dificuldades escolares, aquelas com maior ou menor prejuízo.

Os dois indicadores de desempenho empregados na pesquisa, embora com alguns resultados superpostos, parecem refletir aspectos distintos do desenvolvimento. $\mathrm{O}$ indicador nível de elaboração da escrita se correlaciona, na amostra deste estudo, com recursos ambientais que podem favorecer a aquisição de conceitos lógicos e o desenvolvimento da simbolização, da linguagem oral e da concepção de escrita, com alguma mediação dos pais. Já o indicador atraso se vincula mais fortemente à menor estruturação do tempo em casa, a menos oportunidades de interação com os pais e à presença de situações adversas, sinalizando condições psicossociais que podem interferir com a integração da criança na escola. Essa combinação de baixos níveis de suporte com alta incidência de estressores ambientais configura uma condição de vulnerabilidade (Dubois \& cols., 1992; Dubow \& Tisak, 1989; Masten \& cols., 1988).

Os resultados associados ao atraso escolar devem ser relativizados, dada a forte correlação entre esta variável e a idade cronológica. Não obstante, os resultados da análise de regressão mostraram que o total de recursos disponíveis e a adversidade crônica mantêm relação com o atraso escolar, mesmo quando controlado estatisticamente o fator idade.

Alguns resultados indicam que a distribuição de recursos na amostra é afetada pela condição sócio-econômica. $\mathrm{O}$ acesso a passeios, a brinquedos e a livros está associado a maior conforto, sinalizado pela presença de comodidades no lar. A escolaridade materna também tem correlação com o item comodidades e ainda com o acesso a brinquedos e a livros, que por sua vez se associam com o nível de elaboração da escrita da criança. Pode-se supor que a escolaridade materna seja mediadora entre uma condição financeira mais favorável e a disponibilização, para a criança, de recursos promotores do desenvolvimento.

O número de associações significativas entre características do ambiente familiar e indicadores de desempenho escolar foi pequeno e a magnitude das relações, em geral, apenas moderada. Além disso, o delineamento do estudo apenas permite detectar relações de co-ocorrência e não de causalidade. Dentro desses limites, há coerência entre os resultados obtidos junto a essa clientela de uma clínica-escola brasileira e aqueles derivados de investigações conduzidas na população geral em outros países, sugerindo que recursos do ambiente familiar, favorecedores do desempenho escolar, incluem presença de materiais educacionais e envolvimento dos pais, em forma de participação e organização das rotinas (Bradley \& cols., 1988; Grolnick \& Ryan, 1992; Martini, 1995). Outras tendências relatadas na literatura também se confirmaram nesta população específica, tais como o menor envolvimento dos pais das crianças mais velhas e a associação entre indicadores de envolvimento parental e escolaridade da mãe, sem que esta variável apresente efeito direto sobre o desempenho escolar (Stevenson \& Baker, 1987).

Cabe questionar em que medida as informações obtidas neste estudo podem contribuir para o atendimento psicológico das crianças que apresentam dificuldade na aprendizagem escolar. A esse respeito, pelo menos quatro implicações dos resultados podem ser mencionadas. A primeira diz respeito à necessidade de avaliar cuidadosamente os recursos do ambiente familiar, com vistas ao planejamento da ajuda psicopedagógica. O procedimento de entrevista semiestruturada favorece um rastreamento abrangente, ao mesmo tempo que permite a investigação de particularidades quando isso seja de interesse. Um roteiro para essa finalidade pode incluir tópicos relativos ao funcionamento da criança, de tal forma que este possa ser contextualizado mediante as informações referentes à família.

Uma segunda implicação seria a necessidade de envolvimento dos pais no processo de ajuda. Uma vez identificados, há que ativar e potencializar os recursos do ambiente familiar que facilitam a aprendizagem escolar e o desenvolvimento global da criança. Por exemplo, se as famílias não contam com a possibilidade de visitas a museus, zoológicos ou sítios históricos da cidade, elas podem selecionar e discutir programas de televisão que atendem ao mesmo objetivo. Um simples percurso de ônibus ou a pé pode ser aproveitado para desenvolvimento da linguagem e ativação da 
curiosidade e de processos cognitivos como observação, comparação, formulação de hipóteses...

Kellaghan e cols. (1993) relatam que é possível obter modificação em certas variáveis do ambiente familiar, com intervenção de tempo limitado. Em geral, os pais aceitam pequenas alterações na rotina relacionada à escola quando se demonstra o benefício de tais mudanças; eles podem ser assessorados no relacionamento com a escola de seus filhos; e, mesmo que não possam oferecer materiais de aprendizagem, livros, revistas ou brinquedos promotores do desenvolvimento, eles são capazes de oferecer oportunidades para pensar e imaginar.

Independentemente de ser ou não necessário o acompanhamento clínico, uma terceira implicação diz respeito ao direito, que os pais têm, de acesso à informação sobre o que eles podem fazer para facilitar o aprendizado escolar de seus filhos. Programas informativos em forma de encontros, cursos e vivências podem ser disponibilizados para os pais, atendendo a alguns requisitos como a participação ativa, a oportunidade de compartilhar experiências com outras famílias e o respeito aos seus valores e crenças.

Uma quarta implicação a ser assinalada diz respeito ao enfrentamento das circunstâncias de vida adversas que podem estar contribuindo para as dificuldades atuais da criança. A adversidade está tão presente nas preocupações das famílias que, já na fase de calibração dos instrumentos, o relato espontâneo das mães nos levou a incluir uma lista de condições adversas crônicas na investigação. Os dados demográficos sugerem, para além da presença de adversidades, uma condição de sobrecarga das mães em algumas famílias. Principal fonte de suporte aos filhos, com jornada de trabalho acima de oito horas diárias, acrescida das tarefas domésticas, elas ainda se dispõem a buscar ajuda clínica, o que constitui um ônus adicional. A flexibilidade do horário de trabalho que, na maior parte dos casos, ou está sob o controle da mãe ou pode ser negociado com o empregador, provavelmente funciona como recurso, possibilitando a procura de atendimento clínico. De todo modo, fica claro que, nos casos em que coexistem eventos de vida adversos e sobrecarga materna, não basta informar a mãe quanto às formas de ajudar a criança a enfrentar a dificuldade escolar, pois isso seria acrescentar seus encargos. Sendo ela a principal mediadora do processo de ajuda, é preciso cuidar de seu bemestar psicológico, oferecendo escuta para alívio das tensões e suporte para enfrentamento dos problemas.

Como subsídio às clínicas-escola de Psicologia, cabe lembrar que, sem prejuízo de um trabalho sistematizado de prevenção dos problemas de aprendizagem na instituição escolar, há um espaço importante de atuação do psicólogo na rede de saúde, junto a um segmento expressivo da clientela infantil, constituído por famílias que procuram ajuda para seus filhos em razão de dificuldades escolares. A clínicaescola pode e deve contribuir para a ocupação qualificada desse espaço, implementando práticas de orientação psicopedagógica que possam ao mesmo tempo servir de campo à formação profissional do aluno. As possibilidades de atendimento delineadas acima podem compor um programa in- tegrado de formação teórico-prática para atender a essa demanda.

\section{Referências}

Almeida, S.F.C., Rabelo, L.M., Cabral, V.S., Moura, E.R., Barreto, M.S.F. \& Barbosa, H. (1995). Concepções e práticas de psicólogos escolares acerca das dificuldades de aprendizagem. Psicologia: Teoria e Pesquisa, 11, 117-134.

Berden, G.F.M.G., Althaus, M. \& Verhulst, F.C. (1990). Major life events and changes in the behavioural functioning of children. Journal of Child Psychology and Psychiatry, 11, 949-959.

Bradley, R.H, Caldwell, B.M. \& Rock, S.L. (1988). Home environment and school performance: A ten-year follow-up and examination of three models of environmental action. Child Development, 59, 852-867.

Christensen, S.L. (1990). Differences in students' home environments: The need to work with families. School Psychology Review, 19, 505-517.

Dubois, D., Felner, R.D., Brand, S., Adan, A.M. \& Evans, E.G. (1992). A prospective study of life stress, social support, and adaptation in early adolescence. Child Development, 63, 542557.

Dubow, E.F. \& Tisak, J. (1989). The relation between stressful life events and adjustment in elementary school children: problemsolving skills. Child Development, 60, 1412-1423.

Feldman, S.S. \& Wentzel, K.R. (1990). Relations among family interaction patterns, classroom self-restraint, and academic achievement in preadolescent boys. Journal of Educational Psychology, 82, 813-819.

Grolnick, W.S. \& Ryan, R.M. (1992). Parental resources and the developing child in school. Em M.E. Procidiano \& C.B. Fisher (Orgs.), Contemporary families: A handbook for school professionals (pp. 275-291). New York, Teachers College Press.

Grolnick, W.S. \& Slowiaczek, M.L. (1994). Parents' involvement in children's schooling: a multidimensional conceptualization and motivational model. Child Development, 65, 237-252.

Kellaghan, T., Sloane, K, Alvarez, B. \& Bloom, B.S. (1993). The home environment and school learning: Promoting parental involvement in the education of children. San Francisco: JosseyBass.

Luster, T. \& McAdoo, H.P. (1994). Factors related to the achievement and adjustment of young African American children. Child Development, 65, 1080-1094.

Martini, M. (1995). Features of home environments associated with children's school success. Early Child Development and Care, $111,49-68$.

Marturano, E.M. (1997). A criança, o insucesso escolar precoce e a família: condições de resiliência e vulnerabilidade. Em E.M. Marturano, S.R. Loureiro \& A.W. Zuardi (Orgs.), Estudos em Saúde Mental - 1997 (pp. 130-149). Ribeirão Preto: Comissão de Pós-Graduação em Saúde Mental da FMRP/USP.

Marturano, E.M., Linhares, M.B.M., Loureiro, S.R. \& Machado, V.L. (1997). Crianças referidas para atendimento psicológico em virtude de baixo rendimento escolar: comparação com alu- 


\section{E. M. Marturano}

nos não referidos. Revista Interamericana de Psicologia, 31, 223-241.

Marturano, E.M., Magna, J.M. \& Murtha, P.C. (1993). Procura de atendimento psicológico para crianças com dificuldades escolares: um perfil da clientela. Psicologia: Teoria e Pesquisa, 9, 207-226.

Marturano, E.M., Santos, L.C., Dela Coleta, I.S. \& Matos, E.F. (1997). Recursos no ambiente familiar de crianças com dificuldades escolares [Resumo]. Em Programa de Pós-Graduação em Saúde Mental da FMRP/USP (Org.), $5^{\circ}$ Ciclo de Estudos em Saúde Mental - Resumos (p. 15). Ribeirão Preto: FMRP/ USP.

Marturano, E.M., Alves, M.C.V. \& Santa Maria, M.R. (1998). Recursos no ambiente familiar e desempenho na escola. Em A.W. Zuardi, E.M. Marturano, M.A.C. Figueiredo \& S.R. Loureiro (Orgs.), Estudos em Saúde Mental - 1998 (pp. 48-77). Ribeirão Preto: FMRP/USP.

Masten, A.S., Garmezy, N., Tellegen, A., Pellegrini, D.S., Larkin, K. \& Larsen, A. (1988). Competence and stress in school chil- dren: moderating effects of individual and family qualities. Journal of Child Psychology and Psychiatry, 29, 745-764.

Rende, R.D. \& Plomin, R. (1991). Child and parent perceptions of the upsettingness of major life events. Journal of Child Psychology and Psychiatry, 32, 627-633.

Rutter, M. (1987). Psychosocial resilience and protective mechanisms. American Journal of Orthopsychiatry, 57, 316-331.

Santos, L.C. (1999). Crianças com dificuldade de aprendizagem: estudo de seguimento Dissertação de Mestrado, Universidade de São Paulo, Ribeirão Preto.

Silvares, E.F.M. (1993). O papel preventivo das clínicas-escola de psicologia em seu atendimento a crianças. Temas em Psicologia, 2, 87-97.

Stevenson, D.J. \& Baker, D.P. (1987). The family-school relation and the child's school performance. Child Developement, 58, 1348-1357.

\section{Anexo - Dois Tópicos Ilustrativos do RAF}

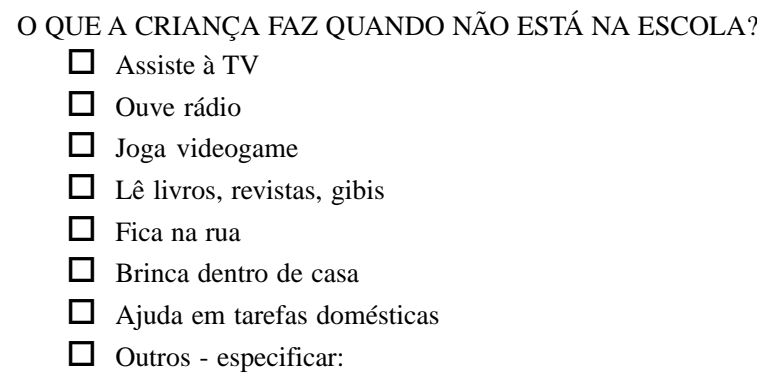

PASSEIO QUE A CRIANÇA REALIZOU NOS ÚLTIMOS 12 MESES

\begin{tabular}{|c|c|c|c|}
\hline passeio & $\begin{array}{l}\text { com } \\
\text { quem }\end{array}$ & passeio & $\begin{array}{l}\text { com } \\
\text { quem }\end{array}$ \\
\hline$\square$ A eroporto & & $\square$ Circo & \\
\hline$\square$ Cinema ou teatro & & $\square$ M useu & \\
\hline$\square$ Shopping Center & & $\square$ Parque de diversões & \\
\hline$\square$ Lanchonete & & $\square$ Clube & \\
\hline$\square$ Praia & & $\begin{array}{l}\square \text { Visitas a parentes / } \\
\text { amigos da família }\end{array}$ & \\
\hline$\square$ Viagem de trem & & $\begin{array}{l}\square \text { Viagem para outra } \\
\text { cidade }\end{array}$ & \\
\hline $\begin{array}{l}\square \text { Sítio, chácara ou } \\
\text { fazenda }\end{array}$ & & $\begin{array}{l}\square \text { Exposição (pintura, } \\
\text { ciências, etc) }\end{array}$ & \\
\hline$\square$ Centro da cidade & & $\square$ Outros - especificar: & \\
\hline
\end{tabular}

